\title{
A AVALIAÇÃO DO REGIME JURÍDICO DA LITIGÂNCIA DE MÁ-FÉ EM PORTUGAL
}

\author{
Susana Antas Fernandes Videira Branco, Joana Cristina Purvis Paixão Campos Carvalho, \\ Tânia Cristina Piazentin Ferreira Mota da Silva e Pedro Miguel Alves Ribeiro Correia
}

EVALUATION OF PORTUGALS' LEGAL REGIME

ON BAD-FAITH LITIGATION

\section{RESUMO}

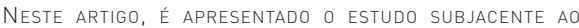
RELATÓRIO DE AVALIAÇÃO DO REGIME JURÍDICO DA LITIGÂNCIA dE MÁ-FÉ leVado a cabo PELA Direção-Geral da Política de Justiça do Ministério da Justiça de Portugal, por MEIO DO QUAL SE PROCUROU AFERIR ACERCA DA ADEQUAÇÃO E EFICÁCIA DO REGIME EXISTENTE PARA EVITAR E/OU COMBATER A PRÁTICA DE ATOS PROCESSUAIS INÚTEIS, DILATÓRIOS OU QUE DETURPAM A REALIDADE DOS FATOS. É FEITA UMA ANÁLISE DO REGIME DA LITIGÂNCIA DE MÁ-FÉ, BEM COMO A SUA DISTINÇÃO DE FIGURAS AFINS, NOMEADAMENTE O ABUSO DE DIREITO DE AÇÃO, A CULPA IN AGENDO, A TAXA SANCIONATÓRIA EXCEPCIONAL E OS INCIDENTES ANÔMALOS. SÃO APRESENTADOS OS RESULTADOS DAS CONSULTAS EFETUADAS, MEDIANTE ENTREVISTA, AOS PROFISSIONAIS DO FORO E ABORDADAS AS ESTRATÉGIAS DE RESPOSTA A ESTA PROBLEMÁTICA, EXISTENTES EM OUTROS PAÍSES

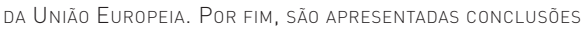
SOBRE A ADEQUAÇ̃̃O DO REGIME ATUAL E ALGUMAS RECOMENDAÇõES, RELACIONADAS À NECESSIDADE DE REALIZAÇĀO DE UM DEBATE ALARGADO E DE CONSCIENTIZAÇÃO DA SOCIEDADE PARA OS PROBLEMAS RESULTANTES DA LITIGÂNCIA DE MÁ-FÉ.

\section{PALAVRAS-CHAVE}

LITIGÂNCIA DE MÁ-FÉ; REgIME JURÍdICO; DIREÇÃo-GERAL dA Política de Justiça; Rede de Cooperação Legislativa dos Ministérios da Justiça da União Europela; Portugal.

\section{ABSTRACT}

THIS ARTICLE PRESENTS THE STUDY UNDERLYING THE EVALUATION REPORT ON THE LEGAL REGIME OF BAD-FAITH LITIGATION, CARRIED OUT BY THE DIRECTORATE-GENERAL FOR JUSTICE POLICY OF THE PORTUGUESE MINISTRY OF JUSTICE, WHICH AIMED AT VERIFYING WHETHER THE CURRENT SOLUTIONS TO AVOID THE PRACTICE OF PROCEDURAL ACTS THAT HAVE THE SOLE PURPOSE OF DELAYING LEGAL PROCEEDINGS OR OMITTING OR MISREPRESENTING FACTS ARE ADEQUATE AND EFFECTIVE. THE ARTICLE ANALYZES THE REGIME OF THE SO-CALLED BAD FAITH LITIGATION, AS WELL AS OTHER REGIMES WITH SIMILAR PURPOSES. IT PRESENTS THE RESULTS OF INTERVIEWS CARRIED OUT AMONGST LEGAL PROFESSIONALS AND APPROACHES THE EXISTING RESPONSE STRATEGIES TO THIS PROBLEM IN OTHER EUROPEAN UNION COUNTRIES. FINALLY, IT PRESENTS CONCLUSIONS ABOUT THE ADEQUACY OF THE REGIME TO AVOID THE PRACTICE OF PROCEDURAL ACTS THAT HAVE THE SOLE PURPOSE OF DELAYING LEGAL PROCEEDINGS OR OMITTING OR MISREPRESENTING FACTS AND PROVIDES RECOMMENDATIONS REGARDING THE NEED TO CONDUCT AN EXTENSIVE DEBATE AND PROMOTE SOCIETY AWARENESS.

\section{KEYWORDS}

BAD-FAITH LITIGATION; LEGAL REGIME; DIRECTORATE-GENERAL FOR JUSTICE POLICY; NETWORK FOR LEGISLATIVE COOPERATION BETWEEN THE MINISTRIES OF JUSTICE OF THE EUROPEAN Union; Portugal. 
O torpe não pode ser útil e nada pode ser lícito não sendo honesto.

(CASTRO, 1616)

In civil proceedings, efficiency does not only depend on internal courts organization or on the way that proceedings are prescribed by law. The parties' behavior and the lawyers' role can have an impact on the length of the proceedings. (EUROPEAN COMMISSION FOR THE EFFICIENCY OF JUSTICE, 2008)

\section{INTRODUÇÃO}

O plano de atividades da Direção-Geral da Política de Justiça (DGPJ) para o ano de 2010 previu a elaboração de um relatório de avaliação do regime jurídico da litigância de má-fé, previsto nos artigos $456^{\circ}$ a $459^{\circ}$ do Código de Processo Civil (CPC) (Decreto-Lei $\mathrm{n}^{\circ} 44.129$, de 28 de dezembro de 1961). A fim de dar cumprimento a essa previsão, uma equipe formada pelos autores, então consultores do Departamento de Política Legislativa da referida Direção-Geral, procedeu à elaboração do estudo em referência (DGPJ, 2010), procurando aferir quanto à respectiva adequação e eficácia para evitar e/ou combater a prática de atos processuais inúteis, dilatórios ou que deturpam a realidade dos fatos.

Note-se, como ponto preliminar, que depois da elaboração do relatório em análise entrou em vigor o novo Código de Processo Civil, aprovado pela Lei no 41/2013, de 26 de junho. Contudo, a plena atualidade do estudo não é afetada, já que o novo Código reproduz, nos artigos $542^{\circ}$ a $545^{\circ}$, praticamente sem alterações, ${ }^{1}$ o regime da litigância de má-fé anteriormente existente.

A oportunidade deste estudo justifica-se à luz da ideia de que o acesso ao Direito e aos tribunais, constitucionalmente consagrado em Portugal, não será efetivo se as decisões não forem proferidas em prazo razoável.

A própria Convenção Europeia dos Direitos do Homem consagra no $n^{\circ} 1$ do artigo $6^{\circ}$ que:

[...] toda a pessoa tem direito a que a sua causa seja examinada equitativa e publicamente em prazo razoável por um tribunal independente e imparcial estabelecido por lei, o qual decidirá quer dos direitos dela e obrigações civis quer sobre o fundamento de qualquer acusação em matéria penal dirigida contra ela. (Lei $n^{\circ} 65 / 78$, de 13 de outubro)

$\mathrm{O}$ artigo $5^{\circ}$ da Convenção - ainda que com um campo de aplicação diferente também estabelece regras para uma justiça célere.

Ora, de acordo com os principais indicadores divulgados online no Sistema de Informação das Estatísticas da Justiça (SIEJ), em 2010 e 2011, a duração média dos 
processos cíveis findos nos tribunais judiciais de $1^{\text {a }}$ instância é de aproximadamente 29 meses.

No que concerne ao movimento processual cível, na última década (20032012), verificou-se um crescimento médio de 3,6\% ao ano, no número de processos pendentes, sendo que em 31 de dezembro de 2012 tal número ascendia grosso modo a 1.525.000. Note-se que estes números são fortemente influenciados pelo peso das ações executivas que, em 2012, correspondiam a cerca de 1.255.000 processos pendentes.

É certo que a diminuição da pendência e a celeridade da decisão não devem ser vistas como valores em si mesmas, até porque a preocupação exclusiva com os números pode comprometer a qualidade das decisões judiciais. Simplesmente, sem prejuízo da relevância que deve ser atribuída à qualidade e à segurança das decisões, é indubitável que a celeridade, instrumento privilegiado de eficácia, não pode ser desconsiderada como fator de promoção e reforço da confiança da comunidade no sistema de Justiça.

Considerando a ausência de dados específicos sobre a utilização do instituto da litigância de má-fé nas Estatísticas da Justiça em Portugal e tendo em conta a conjuntura atual, de aumento da procura dos tribunais (porventura potenciada pelo difícil contexto socioeconômico do país, associado a um crescimento do incumprimento das obrigações), o debate sobre a adequação e eficácia do regime jurídico da litigância de má-fé para prevenir ou sancionar a prática de atos processuais inúteis, dilatórios ou que deturpam a realidade dos fatos assume, portanto, particular relevância, o que justificou o exercício preliminar de avaliação elaborado pela DGPJ.

A redação do relatório preliminar de avaliação deste regime jurídico foi precedida de um conjunto de entrevistas realizadas aos diversos profissionais do foro, incluindo magistrados judiciais, magistrados do Ministério Público, advogados e funcionários judiciais.

A concessão desse plano de consultas tinha como objetivo primacial avaliar se os profissionais consultados recorriam habitualmente ao regime da litigância de má-fé, se o consideravam adequado para evitar a utilização abusiva do processo e quais as principais dificuldades que este lhes suscitava.

Com o intuito de perceber a forma como a litigância de má-fé é evitada e sancionada em outros ordenamentos jurídicos, recorreu-se à Rede de Cooperação Legislativa dos Ministérios da Justiça da União Europeia (RCLUE-NCLEU) difundindo um questionário, em que se perguntou qual o tipo de resposta existente no país para evitar e/ou combater o uso reprovável dos meios processuais, solicitando-se uma breve explicação dos meios existentes, com indicação da sua natureza (legislativa ou outra) e uma tomada de posição acerca da sua adequação e eficácia.

Os dados recolhidos por essa via também constam do relatório de avaliação realizado, o qual está disponível para consulta, no sítio da DGPJ na internet (2010a; 2010b). 
Pretende-se com o presente artigo contribuir para o lançamento da discussão pública em torno do instituto da litigância de má-fé, considerado fundamental pelos profissionais do foro consultados no âmbito do estudo.

\section{O RELATÓRIO PRELIMINAR}

Cumprido o plano metodológico fixado, e no ponto anterior sumariamente descrito, procedeu-se à redação do relatório preliminar de avaliação, o qual contém a enunciação e a análise da situação normativa existente, os resultados das consultas realizadas, a exposição das diversas soluções existentes em outros Estados da União Europeia e a apresentação de conclusões e propostas de eventuais medidas, porventura aptas a tornar mais eficaz o regime jurídico em causa.

\section{CARACTERIZAÇÃo dA SituAÇÃo NORMATIVA EXISTENTE - DisTinÇÃo DE FIGURAS AFINS}

O instituto da litigância de má-fé, em estudo no relatório preliminar objeto deste artigo, distingue-se de outras figuras que visam, de igual modo, dissuadir comportamentos que atentam contra a boa-fé na tramitação processual.

Importa, assim, individualizar aquele instituto, separando-o de outros, como o abuso de direito de ação, a responsabilidade pela ação ou culpa in agendo, a taxa sancionatória excepcional e o agravamento da taxa de justiça nos incidentes anômalos.

\section{I LITIGÂNCIA DE MÁ-FÉ}

Nos termos dos artigos $456^{\circ}$ a $459^{\circ}$ do Código de Processo Civil (correspondentes aos artigos $542^{\circ}$ a $545^{\circ}$ do novo Código de Processo Civil, aprovado pela Lei ${ }^{\circ} 41 / 2013$, de 26 de junho, doravante, NCPC), quem litigar de má-fé será condenado a pagamento de multa e indenização à parte contrária, se esta o pedir.

A multa é fixada dentro dos limites estabelecidos no Regulamento das Custas Processuais (RCP), ${ }^{2}$ entre 0,5 e 5 unidades de conta (UC) - artigo $27^{\circ}, \mathrm{n}^{\circ} 1$, do RCP. Em casos excepcionalmente graves, poderão tais multas atingir as $10 \mathrm{UC}$ (artigo $27^{\circ}$, $\mathrm{n}^{\circ}$ 2, do RCP).

Já a indenização consiste, por força do disposto no artigo $457^{\circ}$ (correspondente ao artigo $543^{\circ}$ do NCPC), no reembolso das despesas a que a má-fé do litigante tenha obrigado a parte contrária, incluindo os honorários dos mandatários e, eventualmente, também na satisfação dos demais prejuízos em consequência, direta ou mediata, da má-fé.

$\mathrm{O} \mathrm{n}^{\circ} 2$ do artigo $456^{\circ}$ (correspondente ao $\mathrm{n}^{\circ} 2$ do artigo $542^{\circ}$ do $\mathrm{NCPC}$ ), por seu turno, considera litigante de má-fé quem com dolo ou negligência grave:

a) tiver deduzido pretensão ou oposição cuja falta de fundamento não devia ignorar; 
b) tiver alterado a verdade dos fatos ou omitido fatos relevantes para a decisão da causa;

c) tiver praticado omissão grave do dever de cooperação;

d) tiver feito do processo ou dos meios processuais um uso manifestamente reprovável, com o fim de conseguir um objetivo ilegal, impedir a descoberta da verdade, entorpecer a ação da justiça ou protelar, sem fundamento sério, o trânsito em julgado da decisão.

A litigância de má-fé apresenta, assim, especificidades quanto à conduta sancionada, à culpa e às consequências. ${ }^{3}$

Por força da base legal citada, só são ilícitas as atuações previstas no $\mathrm{n}^{\circ} 2$ do referido artigo. Quanto à culpa, aspecto que interessa particularmente assinalar, o artigo $456^{\circ}$ do $\mathrm{CPC}$ (correspondente ao artigo $542^{\circ}$ do NCPC) apenas castiga o litigante de má-fé que atue com dolo ou com negligência grave. Por seu turno, a sanção prevista, isto é a multa, não depende da existência de danos causados à outra parte. Já a indenização dos prejuízos causados pela atuação processual é eventual e limitada. Nestes termos, e ao contrário da opção assumida no artigo $465^{\circ}$ do Código de Processo Civil de 1939 (Decreto-Lei $n^{\circ}$ 29.637, de 28 de maio), o regime em vigor sanciona, desde 1995, a par da litigância dolosa, a litigância temerária, na qual as regras de boa-fé que devem nortear a conduta processual das partes são violadas com culpa grave ou erro grosseiro. De salientar, ainda, que a lei processual civil censura a litigância de má-fé, independentemente do resultado. Em uma palavra, o dano não é pressuposto da aplicação da sanção prevista.

Da decisão que condene por litigância de má-fé, independentemente do valor da causa, é sempre admitido recurso em um grau, i.e., da $1^{\text {a }}$ instância para o tribunal da Relação ou deste, quando julgue em $1^{\circ}$ grau, para o Supremo Tribunal de Justiça $\left(n^{\circ} 3\right.$ do artigo $456^{\circ}$; correspondente ao $\mathrm{n}^{\circ} 3$ do artigo $542^{\circ}$ do NCPC).

Quando a parte é patrocinada por mandatário judicial e este teve responsabilidade pessoal e direta nos atos pelos quais se revelou a má-fé na causa, o juiz deve dar conhecimento do fato à Ordem dos Advogados ou à Câmara dos Solicitadores, entidades às quais cabe aplicar a sanção disciplinar que no caso couber. É a disciplina do artigo $459^{\circ}$ (correspondente ao artigo $545^{\circ}$ do NCPC). ${ }^{4}$ Chega-se mesmo a afirmar que "quando a parte é patrocinada por mandatário judicial, dificilmente este não será responsável por algum tipo de atuação de má-fé" (FREITAS et al., 2008, p. 227). ${ }^{5}$

Uma última nota para referir que a condenação como litigante de má-fé deve ser precedida do contraditório, em obediência ao disposto no artigo $3^{\circ}, \mathrm{n}^{\circ} 3$, que pró́be as denominadas decisões-surpresa, posição esta sobejamente sublinhada pela jurisprudência do Tribunal Constitucional, cujo elenco de decisões é apresentado por José Lebre 
de Freitas, Montalvão Machado e Rui Pinto (FREITAS et al., 2008, p. 222-223). Assim, quando não tenha sido objeto de discussão entre as partes, deve o tribunal, antes de proferir a decisão de condenação, proporcionar o contraditório, ouvindo, em particular, a parte contra a qual tem intenção de proferir a condenação como litigante de má-fé.

De qualquer modo, a litigância de má-fé assume-se, hoje, como um instituto processual, de tipo público e que visa ao imediato policiamento do processo. Não se trata de uma manifestação de responsabilidade civil, que visa à supressão de danos, ilícita e culposamente causados a outrem, por meio de um comportamento processual. Corresponde, antes, a um subsistema sancionatório próprio (CORDEIRO, 2011, p. 28).

Por outras palavras, tal como está configurado atualmente, o instituto da litigância de má-fé visa permitir ao juiz, quando necessário, proceder a uma disciplina imediata do processo, oferecendo resposta para atitudes aberrantes, iniquidades óbvias, erros grosseiros ou entorpecimento evidente da justiça. Cumpre saber se tais objetivos estão a ser eficazmente cumpridos, o que justifica o referido exercício de avaliação.

\subsection{OUtros institutos}

\subsection{ABUSO DE DiREITO DE AÇÃO}

Seguindo a lição da doutrina que mais recentemente se vem debruçando sobre o tema, desde o já citado António Menezes Cordeiro e Ana Paula Costa e Silva, passando por Pedro de Albuquerque, a litigância de má-fé não é o único instituto jurídico que permite reagir à utilização ilegítima da ação judicial (ALBUQUERQUE, 2006; SILVA, 2008; CORDEIRO, 2011).

Também o abuso de direito, com base legal no artigo $334^{\circ}$ do Código Civil (Decreto-Lei $\mathrm{n}^{\circ} 47.344$, de 25 de novembro), constitui uma fórmula jurídica tradicional para exprimir a ideia do exercício disfuncional de posições jurídicas. Assume, assim, uma natureza objetiva, tratando-se de uma atuação humana estritamente conforme com as normas jurídicas imediatamente aplicáveis, mas que, apesar disso, se apresenta ilícita por contrariedade ao sistema, na sua globalidade. ${ }^{6}$ Entende, por isso, a doutrina que o abuso de direito é claramente aplicável ao direito de ação judicial e, mais latamente, ao exercício de quaisquer posições no processo (CORDEIRO, 2011, p. 83).

Por consequência, nos casos em que não haja coincidência de pressupostos - porque se existirem, a litigância de má-fé, como regime especial, deve sobrepor-se ao abuso de direito, de ordem geral -, o abuso de direito de ação pode justificar mesmo a propositura de uma ação ad hoc, destinada a apreciar a situação abusiva.

O abuso de direito perfila-se, assim, a par do regime jurídico da litigância de má-fé, como mais um instrumento jurídico passível de ser utilizado para responsabilizar a prática culposa de atos processuais ou a violação de deveres adjetivos, transcendendo, porém, em muito, as margens estreitas da litigância de má-fé, porquanto, em termos 
materiais, é potencialmente aplicável a qualquer violação da boa-fé, dolosa ou negligente, desde que existam danos, quaisquer que eles sejam. Acresce que o abuso de direito permite responsabilizar quer as pessoas físicas, quer as coletivas. ${ }^{7}$

De notar, porém, que, ao contrário da litigância de má-fé, que apresenta um escopo primacialmente punitivo e público, podendo funcionar oficiosamente, o abuso de direito tem uma finalidade preponderantemente privada, em que o tipo de previsão se funda em um conceito indeterminado, e que é de funcionamento oficioso, embora dentro do pedido.

Logo, o abuso de direito de ação faculta aos interessados e, dentro de certa margem, ao próprio tribunal, sancionar as condutas que, embora legitimadas pelo exercício de direitos, se apresentam, todavia, como disfuncionais e contrárias aos princípios gerais de direito.

\subsubsection{A CULPA IN AGENDO}

Outro instituto que o ordenamento jurídico português oferece para reagir ao exercício abusivo do direito de ação é a culpa in agendo ou a responsabilidade pela ação, assente nos artigos $798^{\circ}$ e seguintes, e $483^{\circ}$ do Código Civil.

Com efeito, o exercício do direito ao processo pode resultar de um incumprimento contratual (artigos $798^{\circ}$ e seguintes) - quando, por exemplo, traduza a inobservância de uma convenção arbitral - ou da violação dos mais diversos direitos subjetivos, desde o direito ao bom nome e reputação, ao direito ao patrimônio e à iniciativa econômica, por exemplo, por meio de um pedido de insolvência sem que se verifiquem os pressupostos legais, mas que conduza à paralisação da entidade requerida, caindo, então, na disciplina do $\mathrm{n}^{\circ} 1$ do artigo $483^{\circ}$.

De notar, porém, que o instituto em referência diverge dos anteriores, maxime da litigância de má-fé atendendo ao seu escopo essencialmente privado e ressarcitório. Esta figura assenta em previsão baseada em fórmulas genéricas, está subordinada a pedido e destina-se a obter indenização, a qual segue as regras gerais. Assim, a culpa in agendo permite aos lesados por ações judiciais iníquas e injustificadas o ressarcimento de todos os danos patrimoniais, ilícita e culposamente causados, bem como, nas circunstâncias equivalentes, à compensação por eventuais danos morais.

\subsubsection{TAXA SANCIONATÓRIA EXCEPCIONAL}

O ordenamento jurídico em vigor consagra, ainda, outros instrumentos passíveis de serem utilizados para reagir contra determinadas atuações adjetivas ilícitas e censuráveis.

É o caso da taxa sancionatória excepcional, ${ }^{8}$ prevista no artigo $447^{\circ}-\mathrm{B}$ do $\mathrm{CPC}$ (correspondente, com alterações, ao artigo $531^{\circ}$ do NCPC), onde se lê:

Por decisão fundamentada do juiz, e em casos excepcionais, pode ser aplicada uma taxa sancionatória aos requerimentos, recursos, reclamações, pedidos de 
retificação, reforma ou de esclarecimento quando estes, sendo considerados manifestamente improcedentes: a) Sejam resultado exclusivo da falta de prudência ou diligência da parte, não visem discutir o mérito da causa e se revelem meramente dilatórios; ou b) Visando discutir também o mérito da causa, sejam manifestamente improcedentes por força da existência de jurisprudência em sentido contrário e resultem exclusivamente da falta de diligência e prudência da parte.

Esta taxa de justiça excepcional - variável entre 2 e 15 UC (artigo $10^{\circ}$ do RCP) é, por força da disposição suprarreproduzida, aplicável a várias pretensões processuais que se afigurem manifestamente improcedentes e meramente dilatórias, aduzidas pelos sujeitos processuais com falta de prudência ou diligência. Compulsando a disposição em causa, é mister considerar que o respectivo fundamento está na manifesta improcedência das referidas pretensões processuais, expressando as suas duas alíneas a causa subjetiva e objetiva da respectiva formulação.

Com efeito, em virtude do disposto na alínea a do artigo $447^{\circ}-\mathrm{B}$, para efeitos da eventual aplicação da taxa sancionatória excepcional, as pretensões dos sujeitos processuais, por não se destinarem a discutir o mérito da causa, devem assumir-se como meramente dilatórias e serem o resultado da falta de diligência ou prudência de quem a elas recorre. Já, por força alínea $b$ do mesmo dispositivo, tais pretensões devem visar à discussão do mérito da causa, decorrendo a sua improcedência da existência de jurisprudência contrária e sendo a sua formulação apenas consequência de conduta negligente ou dolosa do sujeito processual que a formulou. ${ }^{9}$

\subsubsection{InCIDENTES ANÔMALOS}

No anterior Código das Custas Judiciais (aprovado pelo Decreto-Lei n ${ }^{\circ} 224-\mathrm{A} / 96$, de 26 de novembro, na redação dada pelo Decreto-Lei no 324/2003, de 27 de dezembro), previa-se no $\mathrm{n}^{\circ} 1$ do artigo $16^{\circ}$ (Taxa de justiça em outras questões incidentais) que:

[...] nas ocorrências estranhas ao desenvolvimento normal da lide que devam ser tributadas segundo os princípios que regem a condenação em custas e na incompetência relativa, nos impedimentos, nas suspeições, na habilitação, na falsidade, na produção antecipada de prova, no desentranhamento de documentos, bem como noutras questões incidentais não referidas no artigo $14^{\circ}$, a taxa de justiça é fixada pelo juiz em função da sua complexidade, do valor da causa, do processado a que deu causa ou da sua natureza manifestamente dilatória, entre 1 UC e 20 UC.

Esta norma conferia ao juiz um poder acrescido de gestão e disciplina da tramitação do processo, não sendo necessário aguardar pelo desfecho da lide para sancionar eventuais comportamentos de abuso processual. 
Com a entrada em vigor do RCP, em 20 de abril de 2009, a tributação dos procedimentos ou incidentes anômalos passou a estar dependente da verificação cumulativa de pressupostos mais exigentes, a saber, que aqueles "possam ter sede em articulado ou requerimento autónomo, deem origem à audição da parte contrária e imponham uma apreciação jurisdicional de mérito" (artigo $7^{\circ}, \mathrm{n}^{\circ} 6$ ).

Esta redação veio, assim, restringir o "campo de aplicação de custas por incidentes, no RCP” (VALLES, 2009, p. 80), sendo em algumas situações possível colmatar esta restrição por meio de aplicação da taxa sancionatória excepcional.

A restrição pode não ser tão acentuada se se entender, como Salvador da Costa, que "a referência à implicação de apreciação jurisdicional de mérito não significa que o incidente ou procedimento deva envolver uma questão de direito substantivo, não excluindo a envolvência de apreciação de meras decisões de questões processuais" (COSTA, 2011, p. 218).

\section{Resultados das consultas}

\section{I ENTREVISTAS AOS PROFISSIONAIS DO FORO}

O relatório a que se refere este artigo procurou apresentar os principais resultados obtidos nas 58 consultas realizadas e que se distribuíram do seguinte modo: 12 realizadas com magistrados judiciais dos tribunais de $1^{\text {a }}$ instância, 38 com magistrados do Ministério Público, ${ }^{10}$ seis com advogados e duas com funcionários judiciais.

No que diz respeito à aplicação prática do regime da litigância de má-fé, a larga maioria dos magistrados judiciais e dos advogados consideram que esta é muito pouco frequente. Já os magistrados do Ministério Público dividem-se, considerando cerca de $2 / 3$ dos entrevistados que o instituto tem aplicação prática e $1 / 3$ que a aplicação é pouco frequente.

Atentando nas respostas quanto às principais dificuldades sentidas na aplicação do regime da litigância de má-fé, constata-se que as várias categorias de profissionais do foro apontam, em linhas gerais, os mesmos constrangimentos, embora a relevância atribuída a cada um destes difira.

A maioria dos consultados considera que as normas do artigo $456^{\circ}$ e seguintes do CPC (correspondentes aos artigos $542^{\circ}$ e seguintes do NCPC) estão bem construídas, não carecendo de alteração. Assim, as principais dificuldades apontadas pelos vários operadores, de acordo com o ilustrado nas figuras seguintes (Figuras 1 a 3), não são legislativas, mas sim:

i) as dificuldades de prova, associadas, por vezes, à própria necessidade de conduzir um novo julgamento apenas para produção de prova quanto aos requisitos da litigância de má-fé; 
ii) o valor reduzido da multa potencialmente aplicável. Os magistrados foram, de forma geral, muito críticos em relação à diminuição dos valores da multa, operada pelo Regulamento das Custas Processuais, qualificando os valores atuais como irrisórios, ridículos e que dão vontade de rir. Referiram mesmo que, tratando-se de um valor tão baixo, compensa arriscar litigar de má-fé, já que, na pior das hipóteses, se for condenado, o máximo que poderá ter de pagar são 1020 euros; e

iii) a postura dos tribunais da Relação que, segundo os consultados, revelam alguma resistência na condenação por litigância de má-fé, o que leva a que os juízes de $1^{\mathrm{a}}$ instância se coíbam de aplicar o instituto com receio de verem as suas decisões revogadas.

FIgURA 1 - NÚMERO DE MAGISTRADOS JUDICIAIS QUE REFERIU

CADA UMA DAS DIFICULDADES DE APLICAÇÃO DO REGIME

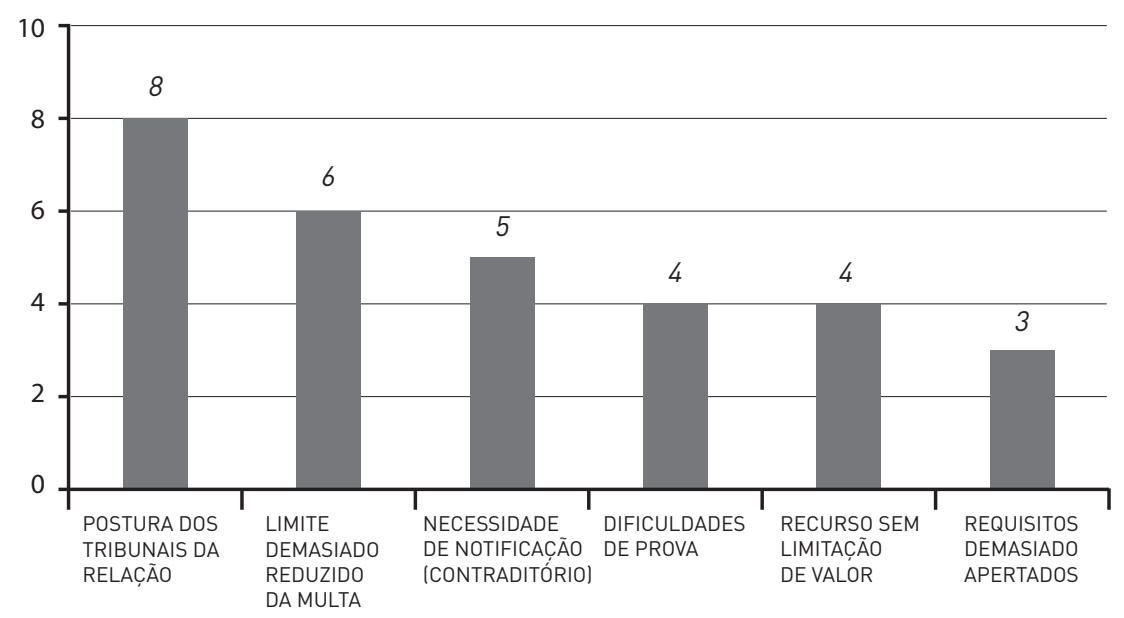

Fonte: Direção-Geral da Política de Justiça, 2010. 
Figura 2 - Número de magistrados do Ministério Público Que REFERIU CADA UMA DAS DIFICULDADES DE APLICAÇÃO DO REGIME

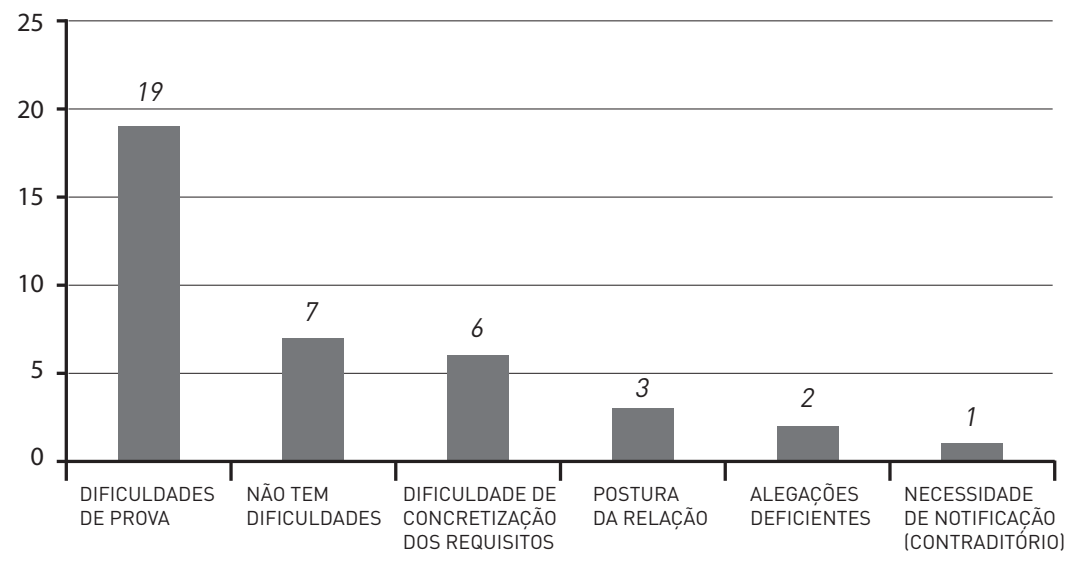

Fonte: Direção-Geral da Política de Justiça, 2010.

Figura 3 - Número DE ADVOGADOS QUE REFERIU CADA UMA DAS DIFICULDADES DE APLICAÇÃO DO REGIME

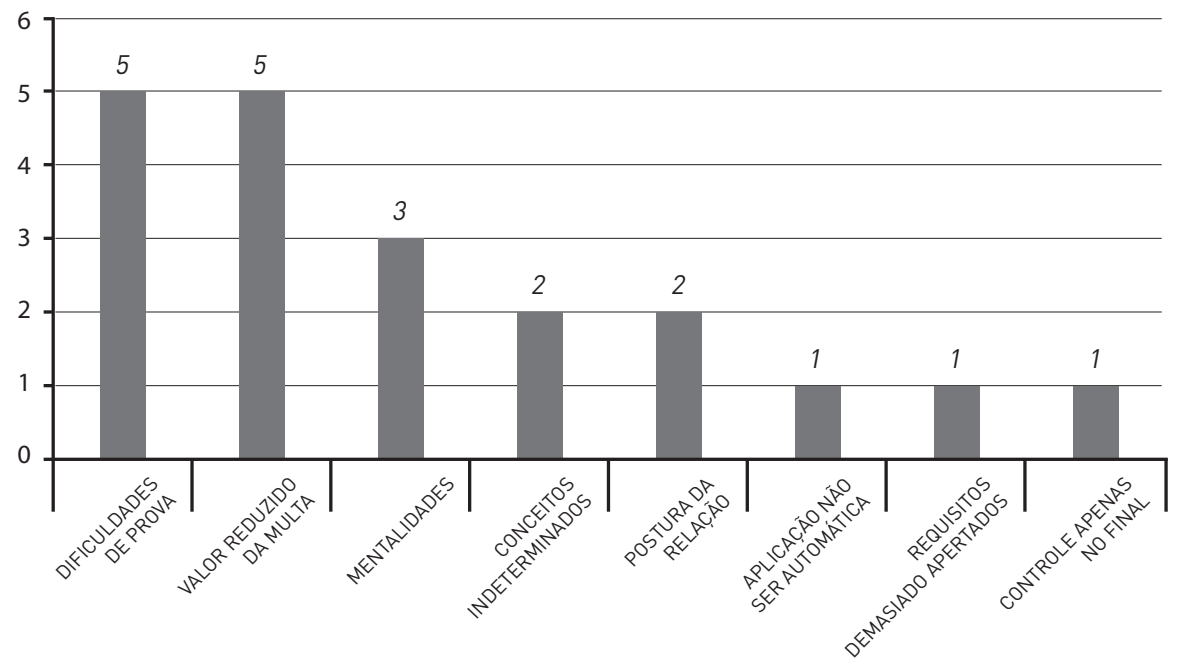

Fonte: Direção-Geral da Política de Justiça, 2010. 


\subsection{Meios de Resposta EXISTENTES EM OUTROS PAíses}

Das respostas recebidas dos Estados-membros da RCLUE- NLCEU - Áustria, Bélgica, Eslováquia, Eslovênia, Espanha, Finlândia, França, Letônia, Lituânia, Reino Unido e Suécia -, foi possível constatar que todos têm normas destinadas a evitar a prática de atos processuais que visam atrasar a ação judicial, que omitem ou deturpam a realidade dos fatos, dificultando, assim, a realização da justiça, ainda que, na maior parte dos ordenamentos, as normas aplicáveis tenham um caráter geral e não regulem especificamente a litigância de má-fé tal como esta se encontra configurada no ordenamento jurídico português (DGPJ, 2010b).

As principais sanções utilizadas neste contexto são as multas, as indenizações, a responsabilidade por custas e/ou despesas da parte contrária, independentemente do desfecho da lide, e a preclusão do exercício de direitos.

Em alguns casos, prevê-se, como forma de garantir o andamento célere do processo, medidas compulsórias tais como detenção para efeitos de comparência no tribunal, ou para prestação da colaboração devida, e a ordem de saída do local da diligência, por comportamento desordeiro.

De referir, dada a sua peculiaridade, o regime do Reino Unido, onde quem litiga habitual e persistentemente sem qualquer fundamento legal é objeto de uma decisão judicial que o impede de propor ações sem autorização prévia do tribunal.

\section{As CONCLUSÕES DO RELATÓRIO PRELIMINAR}

Conforme enunciado na introdução, o objetivo do relatório preliminar em apreço era o de concluir quanto à adequação e eficácia do instituto jurídico da litigância de máfé para evitar e/ou combater a prática de atos processuais inúteis, dilatórios ou que deturpam a realidade dos fatos.

O estudo doutrinário efetuado e o processo de consultas desenvolvido levaram à conclusão de que o regime da litigância de má-fé, consagrado nos artigos $456^{\circ}$ e seguintes do CPC (correspondente aos artigos $542^{\circ}$ e seguintes do NCPC), tem alguma eficácia. Não obstante, registra-se uma aplicação restritiva do instituto, em obediência à ideia, que marca, desde logo, a jurisprudência dos tribunais superiores, secundada pelos magistrados entrevistados, de que este deve ser utilizado, apenas, para comportamentos que configurem exercício abusivo manifesto do direito de ação ou de defesa lato sensu.

No que diz respeito à forma como o regime jurídico da litigância de má-fé está construído, constata-se que este apresenta constrangimentos, relevando, nomeadamente, as dificuldades probatórias dos respectivos pressupostos. Com exceção de um aspecto que trataremos em seguida, estes constrangimentos não reclamam, todavia, uma intervenção urgente do legislador.

O único aspecto do regime da litigância de má-fé que se conclui carecer de atenção urgente por parte do legislador é o limite máximo da multa a aplicar em sede de 
condenação por litigância de má-fé, que, conforme é patente nas entrevistas realizadas, é considerado manifestamente insuficiente, quase irrisório, e, por isso mesmo, dificilmente inibidor de um comportamento processual censurável. A manutenção desse limite é, aliás, de difícil justificação quando o regime criado para a taxa sancionatória excepcional - que tem como pressuposto uma avaliação da prática de atos isolados - prevê, $a b$ initio, uma penalização mais gravosa do que a associada à litigância de má-fé, que assenta em uma avaliação negativa da globalidade da intervenção da parte. Uma alteração legislativa que reveja o limite máximo da multa a aplicar em sede de condenação por litigância de má-fé permitirá, sem dúvida, oferecer maior eficácia ao regime, dissuadindo, mais eficientemente, comportamentos processuais abusivos e justificando a sua aplicação pelos tribunais.

Do estudo realizado, conclui-se, ainda, que as possibilidades que a lei portuguesa consagra para evitar e reprimir comportamentos processualmente censuráveis, algumas das quais deficientemente conhecidas por parte dos utilizadores da Justiça, justificam a sua ampla divulgação, nomeadamente, por meio da discussão pública do tema, que envolva, não só os profissionais do foro, mas também a doutrina que mais se tem debruçado sobre o tema.

\section{ReComendações}

Concluindo-se que o instituto da litigância de má-fé atualmente existente tem de ser aplicado com o maior rigor, a fim de poder contribuir, de forma decisiva, para a realização da Justiça em tempo útil, foram formuladas algumas recomendações finais, com as quais se termina o relatório preliminar em análise.

Parece imprescindível uma alteração pontual de regime, elevando o montante da multa potencialmente aplicável para os níveis previstos no artigo $102^{\circ}$, alínea $a$, do Código das Custas Judiciais, ${ }^{11}$ ou seja, entre 2 e 100 UC.

Resulta dos dados recolhidos que uma discussão dogmática sobre o tema, preparatória de uma ampla reforma legislativa, pode ter efeitos perniciosos, concorrendo para uma acrescida ineficácia do regime, para além de comprometer a certeza e a segurança jurídicas.

Sugeriu-se, ainda, tendo em vista a conscientização, não só dos profissionais do foro, mas de todos os utilizadores da Justiça, uma ampla divulgação do regime, despertando as consciências para os problemas resultantes da sua invocada ineficácia, por meio da realização de debates públicos sobre o tema, foi realizada durante o ano de 2011.

Dando cumprimento a esta última recomendação, realizou-se, no dia 3 de maio de 2011, uma primeira conferência subordinada ao tema $O$ regime jurídico da litigância de má-fé em avaliação, no auditório do Centro de Estudos Judiciários, em Lisboa, organizada conjuntamente pela Direção-Geral da Política de Justiça (DGPJ) e pelo Centro de Estudos Judiciários (CEJ). Pretendeu-se, com essa sessão de apresentação do relatório 
preliminar de avaliação do regime da litigância de má-fé dar início a um amplo processo de discussão pública sobre o tema, que deve envolver não só a academia e os profissionais do foro, mas também todos os utilizadores da Justiça, despertando as consciências para os problemas resultantes de iniciativas e atuações processualmente danosas.

Também com esse propósito de debate aprofundado foi criado, e está disponível no sítio da internet da DGPJ, um espaço permanente, onde qualquer interessado pode deixar o seu contributo ou opinião sobre este regime jurídico. ${ }^{12}$

: ARTIGO APROVADO (04/06/2014) : RECEBIDO EM 04/02/2014

1 A única alteração introduzida traduziu-se na eliminação, no artigo relativo à responsabilidade do representante $\left(544^{\circ}\right.$ no atual Código e $458^{\circ}$ no anterior), da referência às pessoas coletivas. Assim, atualmente, apenas quando a parte for um incapaz, a responsabilidade das custas, da multa e da indenização recai sobre o seu representante que esteja de máfé na causa. Este parâmetro não foi, no entanto, objeto do presente estudo.

2 O RCP foi aprovado pelo Decreto-Lei n ${ }^{\circ} 34 / 2008$, de 26 de fevereiro. Tal diploma, além de revogar o Código das Custas Judiciais, introduz alterações significativas no Código de Processo Civil (CPC), no Código do Processo Penal (CPP), no Código de Procedimento e de Processo Tributário e em outros normativos como o Código do Registo Predial e o Decreto-Lei $\mathrm{n}^{\circ} 108 / 2006$, de 8 de junho, que aprova o regime processual experimental.

3 Com efeito, por força do regime jurídico em vigor, relevam para efeitos de penalização da litigância má-fé três tipos de atuação substantiva e um de natureza eminentemente processual. A título de atuação substancial importam, nos termos do disposto nas alíneas $a, b$ e $c$ do já citado $\mathrm{n}^{\circ} 2$ do artigo $456^{\circ}$ do $\mathrm{CPC}$ (correspondente ao $542^{\circ}$ do $\mathrm{NCPC}$ ), deduzir pretensão ou oposição cuja falta de fundamento se não deva ignorar; alterar a verdade dos fatos ou omitir fatos relevantes para a decisão da causa e a omissão grave do dever de cooperação. Quanto à conduta de natureza processual, o tipo legal apela a um uso manifestamente reprovável do processo ou dos meios processuais, com um de três fins: conseguir um objetivo ilegal, impedir a descoberta da verdade ou protelar, sem fundamento sério, o trânsito em julgado da decisão.

4 De notar que particularmente o Estatuto da Ordem dos Advogados (EOA) contém regras que relevam neste contexto, v.g., o artigo $85^{\circ} \mathrm{n}^{\circ}$ 2, alíneas $a$ e $b$, que consideram deveres do advogado para com a comunidade o de não advogar contra o direito, não usar de meios ou expedientes ilegais, nem promover diligências reconhecidamente dilatórias, inúteis ou prejudiciais para a correta aplicação da lei ou a descoberta da verdade, bem como o de recusar o patrocínio a questões que considere injustas. A violação, dolosa ou meramente culposa, destes deveres constitui infração disciplinar (artigo $110^{\circ}$ do mesmo diploma), sendo o poder disciplinar exercido pelos conselhos de deontologia e pelo Conselho Superior da Ordem dos Advogados (artigos $54^{\circ}$, alínea $a$ e $43^{\circ}, \mathrm{n}^{\circ} 1$, alínea $a$ e 3, alíneas $a$ e $b$ do mesmo Estatuto).

5 Sem prejuízo de a deturpação ou a omissão dos fatos relevantes da causa serem, em princípio, mais imputáveis à parte do que ao seu mandatário, que se presume ter sido por ela deficientemente informado (FREITAS et al., 2008, p. 227).

6 A jurisprudência tem sido determinante na concretização do abuso de direito (CORDEIRO, 2011, p. 81). 
7 Por exemplo, associações, empresas ou fundações, legalmente autorizadas.

8 Por meio da leitura do preâmbulo do Decreto-Lei n ${ }^{\circ}$ 34/2008, de 26 de fevereiro, depreende-se que é objetivo da consagração deste instituto criar um mecanismo de penalização dos intervenientes processuais que, por motivos dilatórios, bloqueiam os tribunais com recursos e requerimentos manifestamente infundados. É precisamente para estes casos que o Regulamento em referência vem atribuir ao juiz o poder de fixar uma taxa sancionatória excepcional, com caráter sancionatório.

9 A taxa sancionatória excepcional, de criação relativamente recente, tem sido alvo de críticas, sobretudo por parte da doutrina processual civil. Com efeito, algumas são as fragilidades do regime e a sobreposição evidente com os pressupostos da litigância de má-fé não acompanhada por idêntico desvalor jurídico - considerando o fato de à taxa sancionatória excepcional corresponder uma sanção mais grave do que a que está prevista para a condenação por litigância de má-fé - é apenas uma delas. Outras dúvidas se colocam, designadamente as de saber se esta taxa de justiça excepcional constitui uma verdadeira taxa ou se, pelo contrário, assume a natureza jurídica de uma multa ou sanção e se esta acresce ou se substitui à taxa de justiça relativa às espécies processuais a que a lei se reporta. Também a utilização, no proêmio do artigo, das expressões em casos excepcionais e pode ser aplicada são objeto de reparo, porquanto, no primeiro caso, a lei expressa os pressupostos de aplicação da sanção nela prevista e, no segundo, tal formulação parece sugerir a ideia de poder discricionário do juiz, o que não é, segundo cremos, a solução legalmente pretendida. De questionar, ainda, na alínea $b$ do artigo $447^{\circ}-\mathrm{B}$, a relevância atribuída à jurisprudência em contrário, sendo certo que as decisões dos tribunais, mesmo os superiores, não constituem fonte de direito em Portugal. Tal previsão pode, ademais, funcionar como um obstáculo a um patrocínio livre e criativo. De resto, o recurso, em larga escala, a conceitos indeterminados - tais como manifesta improcedência, resultado exclusivo da falta de prudência ou diligência e meramente dilatório pode implicar uma escassa aplicação do preceito, por virtude de dificuldade de concretização. Também a solução - idêntica à prevista para a litigância de máfé - de condenar a parte e não o mandatário ao pagamento da taxa sancionatória excepcional pode, na prática, dissuadir o decisor de recorrer a este instrumento. Particularmente, Ana Paula Costa e Silva tem questionado a própria conformidade constitucional da taxa sancionatória excepcional, por a mesma poder não passar pelo apertado crivo do artigo $18^{\circ}, \mathrm{n}^{\circ} 2$ da CRP e por não assegurar a garantia do contraditório ou, na sua refração negativa, a proibição da indefesa (SILVA, 2008, p. 273-287). As dificuldades maiores prendem-se, na ótica desta autora, com o fato de a aplicação da taxa sancionatória estar dependente da ponderação de um elemento subjetivo, porquanto só é devida se o ato praticado for resultado exclusivo da falta de prudência ou de diligência da parte. Por consequência, é neste ponto que a taxa se aproxima muito claramente da multa ou sanção, sendo o seu pagamento devido não porque o ato seja objetivamente inadmissível, mas porque a conduta da parte merece censura ou reprovação. No entendimento da Professora de Direito, a angariação de tributo cede, aqui, com toda a evidência. Esta finalidade é absolutamente marginal. Eis porque entende que tal elemento afasta a possibilidade de a denominada taxa sancionatória ser considerada uma verdadeira taxa, aproximando-a, inequivocamente, das sanções ou penas civis (SILVA, 2008, p. 280).

10 O número significativamente superior de contributos do Ministério Público fica a dever-se ao fato de as procuradorias-gerais distritais, solicitadas a colaborar, terem indicado um número elevado de magistrados, que se disponibilizaram a remeter as suas respostas por escrito.

11 Revogado pelo Decreto-Lei no 34/2008, que aprovou o RCP.

12 Disponível em: <http://www.dgpj.mj.pt/sections/noticias/o-regime-juridico-da6382>.

\section{REFERÊNCIAS BIBLIOGRÁFICAS}

ALBUQUERQUE, Pedro de. Responsabilidade processual por litigância de má-fé, abuso de direito e responsabilidade civil em virtude de atos praticados no processo: a responsabilidade por pedido infundado de declaração da situação de insolvência ou indevida apresentação por parte do devedor. Coimbra: Almedina, 2006.

CASTRO, Fernando Alvia de. Verdadeira razão de Estado: discurso político [1616]. Lisboa: Principia, 2009. 
CORDEIRO, António Menezes. Litigância de má-fé, abuso do direito de ação e culpa “in agendo". 2. ed. Coimbra: Almedina, 2011.

COSTA, Salvador da. Regulamento das custas processuais, anotado e comentado. 3. ed. Coimbra: Almedina, 2011. DIREÇÃO-GERAL DA POLÍTICA DE JUSTIÇA (DGPJ). Regime jurídico da litigância de má-fé: estudo de avaliação de impacto. Lisboa: Ministério da Justiça de Portugal, 2010a. Disponível em: <http://www.dgpj.mj.pt/sections/ politica-legislativa/anexos/avaliacao-do-impacto/estudos-da-dgpj/estudo-de-avaliacao-de/downloadFile/ attachedFile_f0/Relatorio_de_avaliacao.pdf?nocache=1291736795.95 >. Acesso em: 5 out. 2013.

. Anexo 2: mecanismos previstos noutros ordenamentos jurídicos. Regime jurídico da litigância de má-fé: estudo de avaliação de impacto. Lisboa: Ministério da Justiça de Portugal, 2010b. Disponível em:

<http://www.dgpj.mj.pt/sections/politica-legislativa/anexos/avaliacao-do-impacto/estudos-da-dgpj/estudo-deavaliacao-de/downloadFile/attachedFile_2_f0/Contributos_RCLUE.pdf?nocache=1291736795.95 >. Acesso em: 6 out. 2013.

EUROPEAN COMMISSION FOR THE EFFICIENCY OF JUSTICE. European judicial systems - Edition 2008 (2006 Data): efficiency and quality of justice. Council of Europe, 2008. Disponível em: <https://wcd.coe.int/ com.instranet. InstraServlet command $=$ com .instranet. CmdBlobGet\&InstranetImage $=1942681 \&$ SecMode $=1 \&$ Doc Id $=1314568 \&$ Usage $=2>$. Acesso em: 5 out. 2013.

FREITAS, José Lebre de; MACHADO, A. Montalvão; PINTO, Rui. Código de Processo Civil Anotado. 2. ed. Coimbra: Coimbra Editora, 2008, v. $2^{\circ}$, artigos $381^{\circ}$ a $675^{\circ}$.

PORTUGAL. Lei $n^{\circ} 41 / 2013$, de 26 de junho. Diário da República, $1^{\text {a }}$ série, $\mathrm{n}^{\circ} 121$, de 26 de junho de 2013.

. Regulamento das custas processuais, Decreto-Lei n ${ }^{\circ}$ 34/2008, de 26 de fevereiro. Diário da República, $1^{\mathrm{a}}$ série, $\mathrm{n}^{\mathrm{o}} 40$, de 26 de fevereiro de 2008 .

. Código das custas judiciais, Decreto-Lei n ${ }^{\circ} 224-A / 96$, de 26 de novembro. Diário da República, $1^{\text {a }}$ série, nº 274, de 26 de novembro de 1996.

. Convenção Europeia dos Direitos do Homem, aprovada para ratificação pela Lei n ${ }^{\circ} 65 / 78$, de 13 de outubro. Diário da República, $1^{\text {a }}$ série, $\mathrm{n}^{\circ} 236$, de 13 de outubro de 1978.

Código Civil, Decreto-Lei no 47344, de 25 de novembro. Diário da República, $1^{\text {a }}$ série, $\mathrm{n}^{\circ}$ 274, de 25 de novembro de 1966.

Código de Processo Civil, Decreto-Lei no 44129, de 28 de dezembro de 1961. Diário da República, $1^{a}$ série, $\mathrm{n}^{\circ} 299$, de 28 de dezembro de 1961.

Código de Processo Civil, Decreto-Lei n 29637, de 28 de maio. Diário da República, $1^{a}$ série, nº 123 , de 28 de maio de 1939.

SILVA, Ana Paula Costa e. A litigância de má-fé. Coimbra: Coimbra Editora, 2008.

VALLES, Edgar. Custas processuais. 2. ed. Coimbra: Almedina, 2009.

Direção-Geral da Política de Justiça (DGPJ) Av. D. João II, n. ${ }^{\circ} 1.08 .01 \mathrm{E}$, Torre H, Pisos 2/3

1990-097

Lisboa - Portugal

susanavideiraladgpj.mj.pt

Direção-Geral da Política de Justiça (DGPJ) Av. D. João II, n. ${ }^{0} 1.08 .01 \mathrm{E}$, Torre H, Pisos 2/3 1990-097

Lisboa - Portugal joanappcamposlagmail.com

\section{Susana Antas Fernandes Videira Branco}

Doutora EM DiREITO PELA UniversidADE DE LisBoA (UL) Professora da Faculdade de Direito da Universidade dE LISBOA (FDUL)

Diretora-Geral da Política de Justiça (DGPJ) do Ministério da Justiça de PORTugal

\section{Joana C. Purvis Paixão Campos Carvalho}

Doutoranda e Mestre em Direito Pela Universidade Nova DE LISBOA (NOVA) Jurista do BANCO de PORTUgal 
Direção-Geral da Política de Justiça (DGPJ) Av. D. João II, n. ${ }^{0} 1.08 .01$ E, Torre H, Pisos 2/3 1990-097

Lisboa - Portugal tania.piazentinagmail.com

Direção-Geral da Política de Justiça (DGPJ) Av. D. João II, n. ${ }^{0} 1.08 .01$ E, Torre H, Pisos 2/3

Lisboa - Portugal

pcorreialaiscsp.ulisboa.pt

\section{Tânia C. Piazentin Ferreira Mota da Silva}

Licenciada em Direito PELA Universidade de Lisboa (UL) Adunnta do Secretário de Estado da Justiça de Portugal

\section{Pedro Miguel Alves Ribeiro Correia}

Doutor EM CIÊNCIAS SOCIAIS NA ESPECIALIDADE DE Administração Pública PELA Universidade TÉCNICA DE LISBOA (UTL)

PROFESSOR do INSTITUTO SUPERIOR DE CIÊNCIAS SOCIAIS E Políticas (ISCSP) da Universidade dE LisBoa (ULISBOA) INVESTIGADOR INTEGRADO NO CENTRO DE AdMINISTRAÇÃO e Políticas Públicas (CAPP), ISCSP-ULisboa

Consultor da Direção-Geral da Política de Justiça (DGPJ) do Ministério da Justiça de Portugal 
